\title{
Loma Negra: un asentamiento del Periodo Inicial en el litoral casmeño
}

Recibido: 16/11/2017

Aprobado: 01/12/2017
Leonardo Arrelucea Mafaldo

Université de Rennes 1 / Universidad Nacional de Trujillo

< leoarrelucea@gmail.com >

\section{RESUMEN}

El valle de Casma presenta una mayor concentración de sitios monumentales del Periodo Inicial. En contraste existe un vacío arqueológico en cuanto al estudio de los asentamientos domésticos del Periodo Inicial en este valle, (Pozorski y Pozorski 1987). Por otro lado, además del sitio ceremonial de carácter monumental de Las Aldas ubicado en el litoral sur del valle de Casma, no se había reportado evidencia de otro tipo de ocupación del Periodo Inicial en esta área. En 2013, Gabriel Prieto inicia prospecciones arqueológicas en ese sector del litoral de Casma, identificando múltiples sitios entre los que se registran asentamientos domésticos del Periodo Inicial (Prieto y Freire 2013).

En 2015, realizamos una prospección y excavaciones en el litoral Casma Sur (LCS) con el objetivo de identificar asentamientos domésticos contemporáneos a Las Aldas (Periodo Inicial) y del mismo tipo estudiar sus características. En el presente trabajo mostramos los resultados preliminares del sitio "Loma Negra" el cual es a todas luces el asentamiento domestico del Periodo Inicial más extenso reportando hasta la fecha al norte de Las Aldas. En este articulo discutimos las excavaciones realizadas, la función, dieta y tipos de actividades desarrolladas en este sitio que hasta la fecha ha sido desconocido para la ciencia arqueológica.

PALABRAS CLAVE: Periodo Inicial, Casma, Loma Negra, Litoral, Las Aldas

\section{Loma Negra:A Settlement of the Initial Period at the Casma coastline}

\begin{abstract}
The valley of Casma has the greatest concentration of monumental settlements of the Initial Period in the Peruvian Coastline. In contrast, there is an archaeological void regarding the study of non-monumental settlements in this valley as well as lack of studies in the southern section of the Casma littoral.

To fill this gap, in 2015 we conducted a survey and excavations in this area, with the goal of identifying domestic settlements contemporary with Las Aldas and of the same type to study their characteristics. In this paper, I show the preliminary results of the site "Loma Negra". This research is based on the excavations at this site to infer the function, diet and types of activities developed on this site until now unknown for the archaeological community.
\end{abstract}

KEYWORDS: Initial Period, Casma, Loma Negra, Litoral, Las Aldas 


\section{Introducción}

$\square^{1}$ litoral peruano se caracteriza por ser un desierto bañado por aguas frías que sumado a los humedales que se encuentran en él, más fenómenos naturales como es el caso del fenómeno anual de las lomas, lo convierten en un área especial para la concentración de recursos naturales que pueden ser aprovechados por el ser humano. En este sentido la costa peruana se caracterizó por presentar una ocupación intensa y compleja desde el Pleistoceno Tardío hasta la actualidad, como bien documentan los restos de Huaca Prieta en la costa norte o Quebrada de los Burros en la costa sur (Dillehay, 2016; Bird, 1985; Lavallée y Julien, 2012).

De esta manera entre el segundo y tercer milenio a.C surgieron importantes centros cívico - religiosos que presentan una arquitectura de carácter monumental ${ }^{1}$ en casi todos los valles medios y bajos que corresponden a la costa peruana (Moseley, 1975; Fung, 2004[1972]; Kaulicke, 2010). El valle de Casma no está exento de este fenómeno arquitectónico ocurrido en los Andes Centrales, siendo uno de los valles en los que se ha identificado una mayor cantidad de ocupación perteneciente a este lapso (Fig.1).

Julio C. Tello fue el primer arqueólogo en prestarle atención a esta parte de la costa peruana cuando en 1937 , como parte de la famosa "Expedición Arqueológica al Marañón”, recorrió el valle y logró identificar más de 20 sitios, entre templos, caminos, y aldeas, la mayoría asignable al Periodo Inicial, concentrando sus esfuerzos en Cerro Sechín (Tello, 1956). Lamentablemente Tello nunca visito el litoral casmeño, por lo que no pudo reportar los sitios ubicados en esta área del valle (Prieto y Freire 2013).

En 1956 Donald Collier realizo una prospección al valle de Casma, en la que cubría también el valle bajo y el litoral casmeño, aunque redujo su prospección a la desembocadura de los ramales Sechín y Casma, siendo el primero en reportar los sitios costeros de Huaynuná y Tortugas (Collier, 1962). Por su parte Edward Lanning y Frederic Engel, también recorrieron el litoral casmeño, como parte de un mega proyecto

1 Si bien hasta la fecha existen diversas posturas acerca del proceso constructivo y de las formas de organización social que las permitieron, no es uno de los objetivos de este articulo discutir sobre el surgimiento de la arquitectura monumental en los Andes, debemos mencionar que las evidencias en diversos asentamientos del Periodo Inicial indican una sociedad jerarquizada, como bien lo explica Richard Burger tras sus trabajos en el valle de Lurín (2009: 17 -36). emprendido por el último, el cuál buscaba estudiar los asentamientos prehispánicos ubicados en la costa desértica peruana. En 1956 logró identificar el sitio de Las Aldas, y más de 100 sitios ubicados en el litoral al sur de Las Aldas y alrededor de Cerro Mongón (Engel 1970:39). Lamentablemente Engel nunca publicó información detallada de estos asentamientos, aunque gracias a los trabajos de Santiago Uceda en dicha zona hoy sabemos que al menos algunos sitios ubicados cerca al Cerro Mongón fueron muy tempranos, con una industria lítica similar a la Paijanense (Uceda, 1992: 45- 67).

Desde 1956 en adelante, el valle de Casma y los sitios conocidos tanto en el litoral como en el valle, correspondientes al Periodo Inicial, fueron objeto de diversas investigaciones como la Primera Expedición Científica Japonesa a los Andes que tenía como uno de sus objetivos conocer el "Origen de la civilización en los Andes”, realizando excavaciones en Las Aldas, acompañados de la arqueóloga peruana Rosa Fung y efectuando algunos cateos y trincheras en la parte del templo del asentamiento (Kaulicke, 2010:158). Como parte de su tesis doctoral en 1967, Rosa Fung realiza nuevas excavaciones en el templo de Las Aldas, identificando una ocupación que databa desde el Precerámico Tardio (circa 2500-1800 a. C.) hasta una ocupación del Horizonte Temprano (circa 500 a.C- 200 d. C.). El detallado análisis de los materiales excavados por Fung, le permitió postular que Las Aldas fue un punto de contacto entre las poblaciones de la costa central y la costa norte, haciendo comparaciones con sitios como Ancón y Cerro Negro de Guañape (Fung, 1969). También realizo excavaciones en el área domestica del sitio que se ubicaban al sur, pero no publico información detallada de la misma.

En adelante diversos investigadores se preocuparon por esteimpresionantesitio del litoral del valle de Casma, la mayoría incidiendo en el templo, coincidiendo con los trabajos de Fung. (Grieder, 1975; Matsuzawa, 19782). A finales de 1979 e inicios de 1980, Shelia y Thomas Pozorski realizaron prospecciones en el valle y excavación de cateos en algunos sitios seleccionados, a fin de conocer la subsistencia y el desarrollo social del valle de Casma, desde el Precerámico Tardío hasta el Horizonte Temprano (Pozorski y Pozorski, 1987: 1-5).

\footnotetext{
2 Si bien este artículo se publica mucho después de la tesis de Fung, en realidad es un resumen de los trabajos de 1958 y de 1969, es decir de las dos temporadas de excavación que tuvo la misión japonesa en Las Aldas.
} 
Serían estos últimos investigadores los que hasta la fecha han realizado la mayor cantidad de investigaciones en la zona de Casma, haciendo importantes aportes para el entendimiento del desarrollo social de este valle. Para los fines que nos corresponde, debemos mencionar que los Pozorski realizaron importantes excavaciones en sitios del litoral como son Huaynuná, Tortugas, Bahía Seca y Las Aldas. (Pozorski y Pozorski, 1998, 2008).

Cabe resaltar que ninguno de los investigadores mencionados a excepción de Uceda, alude los sitios ubicados al norte de Las Aldas (litoral sur del valle de Casma), y los ubicados cerca al cerro Mongón. Sin embargo, no es hasta el ańo 2013, cuando Gabriel Prieto realiza prospecciones en esta zona entre Punta Huaro y la caleta La Gramita, identificando 11 nuevos sitios en el litoral sur del valle de Casma, proponiendo una ruta de recursos marinos, del litoral a la zona del valle de Casma (Prieto y Freire, 2013: 106-111). En esa oportunidad Prieto y Freire sólo detallan tres sitios de los 11 que pudieron identificar.

El año 2015 con motivo de ampliar las investigaciones en los sitios identificados y su relación con el centro de Las Aldas, Gabriel Prieto y su equipo condujeron excavaciones en cinco zonas arqueológicas, incluyendo el área domestica ubicada al noroeste de Las Aldas donde nunca se habían realizado excavaciones, logrando identificar diversos momentos ocupacionales en cada uno de los asentamientos excavados. Con respecto a Las Aldas, identifica una intensa ocupación domestica correspondiente al Periodo Inicial (Prieto et al. 2017).

Uno de los sitios identificados y excavados por Prieto y equipo, es el sitio de Loma Negra, el cual se nos encargó las investigaciones y análisis de los materiales identificados como parte del "Proyecto Arqueológico Litoral Casma Sur”.

\section{El litoral del valle de Casma: geografía y ecología}

El litoral sur del valle de Casma se compone por una variada alternancia de puntas, ensenadas y playas con un fondo marino tanto tipo rocoso como de tipo arenoso. Por lo general estas playas son bahías o ensenadas que van alternándose con barrancos a lo largo de todo el litoral. Por otro lado, estas playas en las rompientes rocosas del litoral se pueden apreciar una gran cantidad de diferentes tipos de algas, mientras las playas de tipo arenoso suelen ser bahías o ensenadas de aguas azuladas.

El litoral suele ser desértico y estar salpicado de amplios tablazos, así como algunas estribaciones entre las cuales destaca el Cerro Mongón, el cual es ostenta ser el más alto de la costa del Perú (Engel, 1970). Estos tablazos y estribaciones suelen formar entre los meses de mayo a octubre, un ecosistema de loma, lo cual es común en la costa del Perú, llenando de vegetación esta área desértica.

Entre las especies vegetales más comunes que se pueden identificar en esta zona están las achupallas (Tilandasia sp.) y todas las especies de la familia de las Bromeliáceas, en algunas zonas de lomas se pueden apreciar arboles aislados de huarango (Acacia macracantha) y tara (Caesalpina spinosa). A lo largo de este variado litoral, hemos podido identificar la presencia de lobos marinos y abundancia de aves marinas las cuales suelen anidar en los islotes que proliferan en la zona, cubriéndolos de una densa capa de guano (Fig.2).

Actualmente la zona es visitada por una importante cantidad de pescadores y mariscadores que suelen visitar sus playas cada mañana, recolectando diferentes mariscos entre los que destacan: Concholepas concholepas, Chiton sp. diferentes tipos de "lapas" (Fissurella sp.) y caracolitos negros (Prisogaster niger). En cuanto a especies de peces se puede observar que los botes suelen capturar principalmente especies como Corvina (Cilus gilberti), Doncella (Coris julis) y Pintadilla (Cheilodactylus variegatus), que se caracterizan por ser especies con un importante volumen cárnico.

Bajo esta perspectiva, se trata de un litoral que permite el acceso a una amplia gama de recursos marinos, debido a que se pueden acceder a recursos de ecosistemas marinos rocosos y ecosistemas marinos arenosos, no solo en cuanto a peces sino a aves y a mamíferos marinos, además de la presencia del ecosistema de lomas que permitiría (eventualmente) el acceso a algunos cultígenos temporales.

Asentamientos Tempranos en el litoral Casmeño

Resulta interesante observar que los asentamientos del litoral del valle de Casma han sido estudiados desde la década de 1950 en adelante, en comparación a otros sitios del litoral como Huaca Prieta, Áspero, Ancón otros que han sido estudiados desde casi los inicios de la arqueología científica en Perú es decir inicios del siglo XX (Uhle, 1906; Bird, 1985; Feldman, 1985; Rosas, 1970). 
Pese a tratarse de un litoral que mide aproximadamente 52 kilómetros, en los cuales se puede observar una importante presencia de pesca y marisqueo artesanal, que denota la riqueza de su biomasa marina, que a su vez atrae aves y mamíferos marinos, sin embargo, llama la atención que en esta amplia y rica costa solo se hayan identificado tres asentamientos tempranos en toda esta costa, y aún más cuando probablemente esta zona haya tenido humedales como sucede en otros valles y cuyos relictos aún quedan como sucede en el caso de Bandurria, en el valle de Huaura (Chu, 2008).

A continuación, presentaremos las principales características de estos tres asentamientos como son Tortugas, Bahía Seca y Huaynuná

Huaynuná es el asentamiento más norteño del litoral de Casma, ubicado en la bahía del mismo nombre. Fue excavado por Donald Collier y Frederic Engel, aunque los trabajos más importantes se los debemos a Shelia y Thomas Pozorski que excavaron 16 cateos en este asentamiento, logrando obtener fechados radiocarbónicos que lo ubican entre el 2200 y 1700 a.C (Pozorski y Pozorski, 1987: 12-13). Posteriormente estos últimos investigadores darían cuenta de dos componentes más tardíos del sitio, asignables al Periodo Inicial y Horizonte Temprano, aunque no ahondan en datos sobre estos dos componentes, logran identificar dentro del componente Precerámico, un montículo del cual obtuvieron restos de Solanun tuberosum, Ipomea batatas, y Canna edulis, es decir varios tubérculos que fueron cultivados en otros ambientes y zonas geográficas. También lograron identificar un sector doméstico en el que identifican artefactos de concha, muros de piedras y algunas redes (Pozorski y Pozorski, 1990: 17-19).

Estas investigaciones se concentraron en definir la naturaleza de un montículo ubicado en la ladera, el cual luego de las excavaciones mostró ser un conjunto de ocho terrazas, divididas en cuatro a lado de manera simétrica divida por una escalera central, teniendo en su cima un área plana y amplia, con un posible pozo circular pequeño, siendo fechado entre el 2180 \pm 230 a.C (sin calibrar). Para los Pozorski esta área probablemente sirvió para la realización de actividades públicas, identificando una ruta "privada" y una publica de acceso a esta área. Otros fechados provenientes de Huaynuná sugieren una ocupación del Periodo Inicial entre el 1650 y 1560 a.C, aunque los investigadores mencionan el no haber identificado restos de cerámica (Pozorski y Pozorski, 1999: 176-178).

Tortugas, es otro asentamiento de litoral, ubicado en la bahía del mismo nombre, se trata de un asentamiento con un componente Precerámico y otro del Periodo Inicial. Con respecto a esta última ocupación, la primera descripción se la debemos a Rosa Fung, quien describe la cerámica del sitio como similar a la de la primera fase de Las Aldas, estableciendo un complejo que denomino Las Aldas-Sechín Alto (Fung, 1972: 21-25). Shelia y Thomas Pozorski, que condujeron excavaciones en el sitio, identifican al igual que en Huaynuná una construcción en la ladera, la cual también presenta una estructura circular en su montículo. Identifican bordes de cerámica de ollas sin cuello, y observan que el principal patrón de decoración de la cerámica es una puntuación profunda y angular ubicada en el hombro de las ollas sin cuello, lo cual junto a los fechados radiocarbónicos presentados que varían entre el 2100 y 1800 a. C., hacen que los investigadores realicen paralelos entre Tortugas y Pampa de las Llamas-Moxeke (Pozorski y Pozorski 1987: 46-49). Por otro lado, es interesante mencionar los restos botánicos identificados en el sitio, como son el ají (Capsicum sp.), papa (Solanun tuberosum), camote (Ipomea batata), jíquima (Pachyrrhizus tuberosus) y yuca (Manihot esculenta) (Ugent et. al 1986: 90-92), lo cual demuestra una interesante variedad de tubérculos consumidos en el asentamiento.

Bahía Seca es un asentamiento doméstico, al igual que los dos mencionados anteriormente, ubicado en la bahía del mismo nombre. Se trata de un asentamiento con componentes del Precerámico Tardío y el Periodo Inicial, podemos mencionar que este sitio también se encuentra en la ladera de una colina. Se ha podido identificar habitaciones cuadrangulares, con esquinas rectas y redondeadas, con similar característica a las identificadas en Pampa de Las Llamas-Moxeke y Taukachi-Konkan con cerámica del mismo tipo (Pozorski y Pozorski, 2008: 620). De igual manera se ha identificado un conjunto circular con un fogón circular, que data entre $3280 \pm 55$ a. C. (no calibrado), cuyos muros fueron construidos con material perecible (Pozorski y Pozorski, 1996: 343, tabla 1, 347, Fig.6).

En resumen, estos son los tres sitios ubicados en el litoral casmeño, correspondientes al Periodo Inicial, reportados hasta la fecha, ubicados todos en la parte norte del mismo, quedando el parte sur del litoral, únicamente el centro monumental de Las Aldas, 
notándose un gran vacío en el litoral sur, como se puede observar en casi todos los mapas publicados para el valle en las distintas publicaciones citadas en este trabajo.

Para los asentamientos de Tortugas, Bahía Seca y Huaynuná se ha planteado una relación de centroperiferia, o de centro-satélite, siendo estos la periferia y satélites de las grandes urbes del valle medio como Pampa de Las Llamas-Moxeke y Sechín Alto, en este modelo, serían los satélites quienes proveían de proteína marina y recursos marinos a las poblaciones del valle medio, siendo los primeros dependientes de los últimos (Pozorski y Pozorski, 1998; 2008). Ciertamente a la luz de las evidencias mostradas en otros sitios del Periodo Inicial como los del valle de Lurín o Gramalote (Prieto, 2015), creemos que este modelo debe ser reevaluado y deberían ser estudiados con mayor profundidad y extensión los asentamientos de litoral, a fin de conocer su naturaleza ocupacional, así como el carácter particular de este tipo de asentamientos.

El sitio de Loma Negra, recientemente identificado para la ciencia arqueológica es un buen candidato para estudiar más a fondo la naturaleza doméstica y residencial de este tipo de asentamientos en relación con los centros monumentales ceremoniales del Periodo Inicial en el valle y litoral de Casma.

\section{Loma Negra un asentamiento en el litoral casmeńo: descripción y excavaciones}

Como bien habíamos mencionado producto del reporte de Gabriel Prieto y Fernando Freire en el litoral sur del valle de Casma, en el ańo 2013, el año 2015 el primero gracias a una beca otorgada por la National Geographic y la Waitts Foundation, se logra obtener el permiso correspondiente para la excavación y prospección en el litoral sur del valle de Casma, proyecto al cual fuimos invitados para encargarnos de las labores de campo y análisis de los materiales, principalmente los que puedan ser asignados al Periodo Inicial.

Las labores de reconocimiento y excavación ocurrieron entre los meses de octubre y diciembre, siendo Loma Negra, el tercer sitio en el cual realizamos labores, el cual ya había sido reconocido por Prieto en su prospección del 2013 (Prieto y Freire 2013).

Este sitio se ubica aproximadamente a unos 10 kilómetros al sur de la desembocadura del Rio Casma e inmediatamente al norte de la playa Cajero chica, a 40 m.s.n.m. El sitio mide unos 90 metros en su eje este-oeste y unos 60 metros en su eje norte-sur, inmediatamente al norte se puede observar una bahía de tipo arenosa, mientras al sur del asentamiento, se encuentran peñas y barrancos de tipo rocoso, la ubicación del asentamiento resulta estratégica pues se ubica en una colina que permite observar al norte la bahía y al sur las peñas y barrancos, permitiendo observar recursos de ambos tipos de ecosistema marino (Fig.3).

El asentamiento comprende una serie de aproximadamente cuatro terrazas ubicadas al lado derecho y cuatro al lado izquierdo, las cuales están divididas por una aparente escalera central. Esta escalera conecta al asentamiento directamente con la bahía arenosa, y a su vez a la cima de la colina donde se puede observar un área plana cubierta de ceniza, fragmentos de moluscos y restos de tallas líticas. es en esta área en donde pudimos identificar los restos de un posible mortero decorado, realizado en andesita (Fig.4) de igual manera, en esta misma área se pudo observar un pequeño pozo el cual mide aproximadamente 4 metros de diámetro, todos los muros, el pozo y la escalera están construidos con piedras de la zona, donde abunda la andesita.

Con la descripción presentada podemos notar que se trata de un asentamiento que comparte un plano similar a Huaynuná, Tortugas y Bahía Seca (Pozorski y Pozorski, 1999). Aunque debemos aclarar que no hemos podido notar la presencia de un templo en Los Pelicanos como sucede con Huaynuná mientras que la comparación que hacemos con Tortugas es en base a las hipótesis de los Pozorski (Ibidem) ya que la información publicada sobre este asentamiento sigue siendo muy fragmentaria hasta la actualidad.

Decidimos realizar prospección de transectos cruzados a fin de reconocer el sitio, pudimos notar que la piedra utilizada para la elaboración de los muros fue obtenida directamente de la colina donde se ubica el asentamiento, y que aparentemente se trata de muros con doble cara, como mencionamos anteriormente en toda la superficie del asentamiento se puede observar ceniza mezclada con fragmentos de moluscos, algunos fragmentos de cerámica, la mayoría no presentaban decoración, también pudimos identificar la presencia de algunos artefactos líticos como la base de un mortero de piedra (andesita) la cual presentaba decoración, así como algunas lascas y raspadores . 
Decidimos realizar las excavaciones entre uno de los alineamientos de piedras que dividían las terrazas, para poder conocer la posible estratigrafía de una de estas. Logramos identificar seis pisos ocupaciones, con una profundidad de 1.65 metros. Decidimos excavar registrando de manera gráfica, fotográfica y altimétrica cada piso ocupacional con sus respectivos contextos y cada relleno del mismo. De esta manera pretendíamos conocer no sólo la estratigrafía del sitio, sino también nos permitiría conocer a través del relleno la variedad de recursos a los que estos tenían acceso y como iban variando los mismos a nivel estratigráfico.

El primer piso ocupacional, fue identificado a unos 20 centímetros de la superficie en promedio, se trataba de un piso irregular de color amarillo, con presencia de arena y ceniza entre dos a tres centímetros de grosor, el segundo piso se encontraba fuertemente salitrado en su lado sureste, la concentración de salitre llegaba hasta los casi 7 centímetros de espesor, de igual manera todos los pisos ocupacionales presentaban un color entre el crema y el amarillo claro y un espesor promedio entre dos y tres centímetros.

En el relleno de capa uno, es decir entre los pisos ocupacionales uno y dos, se pudo identificar tres piedras angulosas entre 20 y 30 centímetros de largo, durante nuestra excavación en lo que sería el piso ocupacional cinco o capa cinco, pudimos identificar en la esquina sur este de la excavación un alineamiento de piedras angulosas canteadas de aparente forma circular el cual hasta donde pudimos medir tenía 25 centímetros de diámetro, conteniendo una importante concentración de carbón en su interior por tratarse de un contexto primario, decidimos sacar muestras para futuros fechados radiocarbónicos.

Absolutamente todos los rellenos de capa se caracterizaban por la fuerte presencia de ceniza, dificultando la excavación, dentro de los rellenos pudimos encontrar abundante material cerámico, restos de moluscos y crustáceos, de peces y aves, lo curioso es que estos pocos huesos que se pudieron conservar mostraban huellas de quema, y en cuando al material botánico, este era muy escaso, por efectos de logística tuvimos que detener nuestras excavaciones hasta identificar nuestra capa ocupacional seis, por lo que no tenemos claro hasta donde llega la estratigrafía del asentamiento, para poder postular un probable inicio y fin de ocupación relativa.

\section{Loma Negra: Un asentamiento del Periodo Inicial}

Gracias a nuestras excavaciones — si bien no pudimos llegar a capa estéril—, podemos postular en base a los estilos decorativos de la cerámica que este asentamiento, que no había sido estudiado ni reconocido por la comunidad científica anteriormente, que se trata de un asentamiento residencial del Periodo Inicial.

La cerámica encontrada en nuestras excavaciones fue estudiada de forma tipológica, tecnológica y a nivel de decoración a fin de establecer comparaciones con otros asentamientos. Pudimos notar que entre las formas identificadas destacan las ollas sin cuello de labio redondeado con refuerzo en su interior (borde en coma) y un ejemplar de olla con cuello ligeramente entrante. Las inclusiones suelen ser cuarzo, arena y concha molida, los diámetros de la boca de las ollas varían entre los 10 y 15 centímetros, por lo que se trata de ollas de tamaño mediano, donde el diámetro de la boca debió ser menor al diámetro del cuerpo. Todos los fragmentos presentaban huellas de hollín en su exterior, estas ollas sin cuello posiblemente presenten un cuerpo globular (Fig.5).

En cuanto a la decoración pudimos identificar tres tipos decorativos, todos identificados en sitios del Periodo Inicial: incisiones, punteados y listones.

Se identificó un fragmento con incisión de línea ancha poco profunda, , un fragmento decorado con listón, el cual presenta incisiones hechas probablemente con caña, semejantes a los reportados en Huaca Negra, como decoración típica del Guañape Medio (Strong y Evans, 1952) aunque debido a que la seriación de la cerámica temprana del valle de Virú, se trata de una seriación en base porcentual, mas no estratigráfico resulta poco confiable establecer un paralelo temporal, por otro lado lo que si pudimos observar es la presencia de fragmentos escarificados y semi-escarificados, de igual manera fragmentos con puntuado circular y ovoide los cuales son muy populares en el sitio de Las Aldas identificados por Fung. Principalmente en lo que ella denomina "Fase Transicional" y Fase II de Las Aldas (Fung, 1969: 70-77).

Como bien habíamos mencionado anteriormente, los restos botánicos al igual que los restos de aves y peces, se encontraban en mal estado de conservación, empero pudimos identificar algunas especies como son Canna edulis, Solanun tuberosum, Tilandasia sp., Pouteria lucuma y la especie que sobresalía en cantidad y grado de conservación era Capsicum sp. (Fig.6) de la 


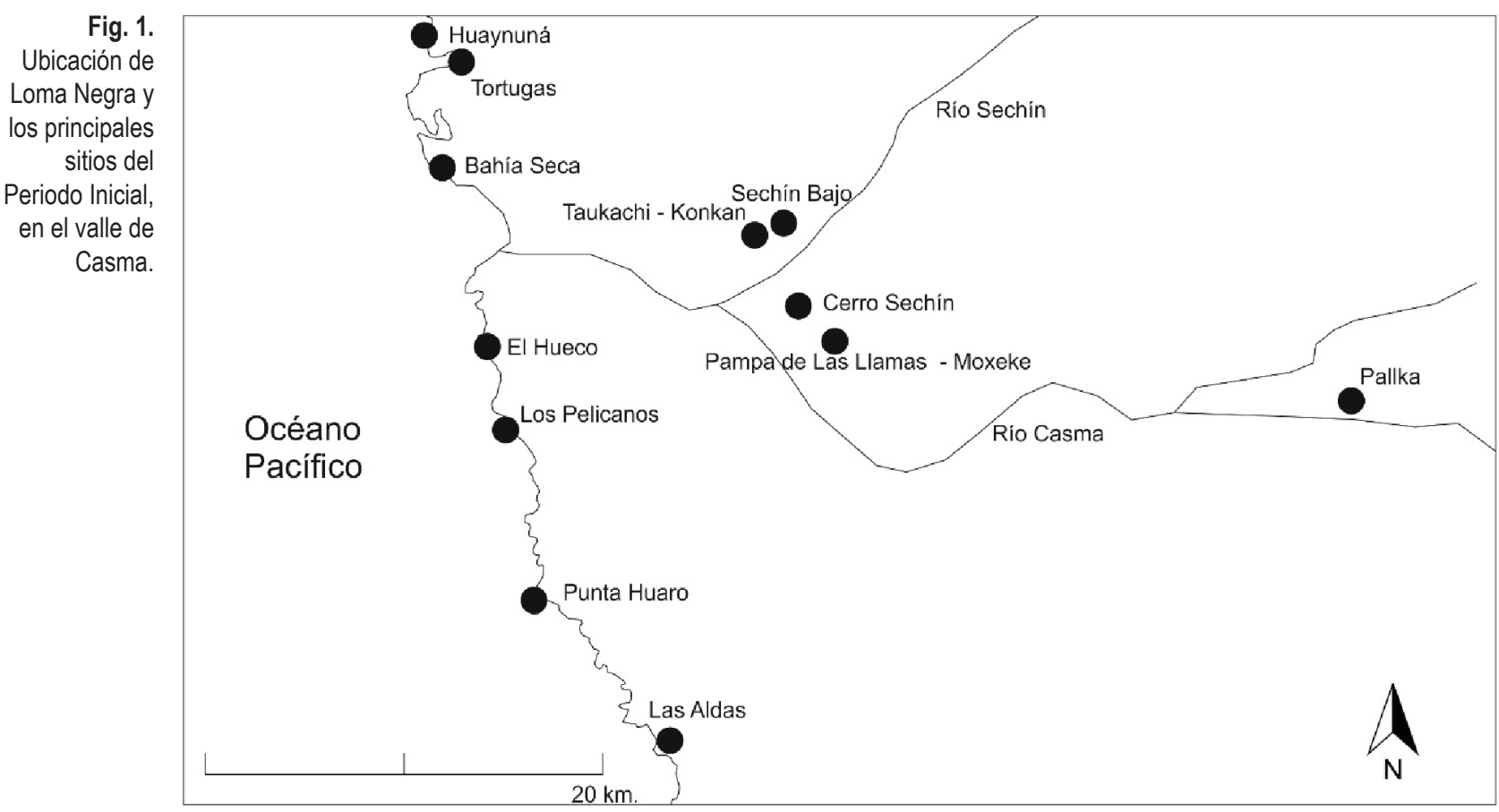

Fig. 2. Actual colonia de Lobos marinos en el litoral casmeño (Fotografía: Leonardo Arrelucea)
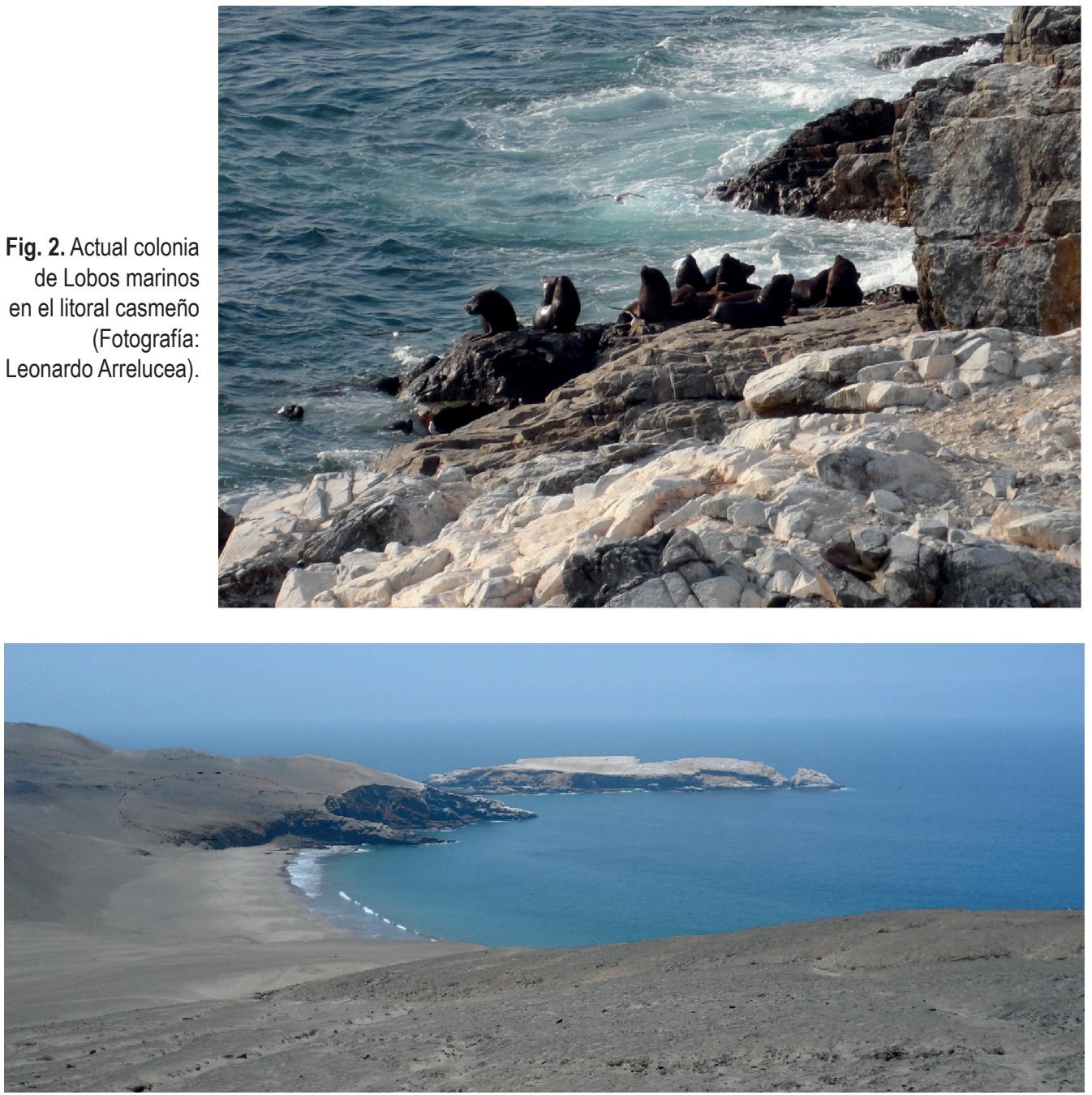

Fig. 3. Vista de Loma Negra, y su entorno geográfico desde el norte (Fotografía: Leonardo Arrelucea). 


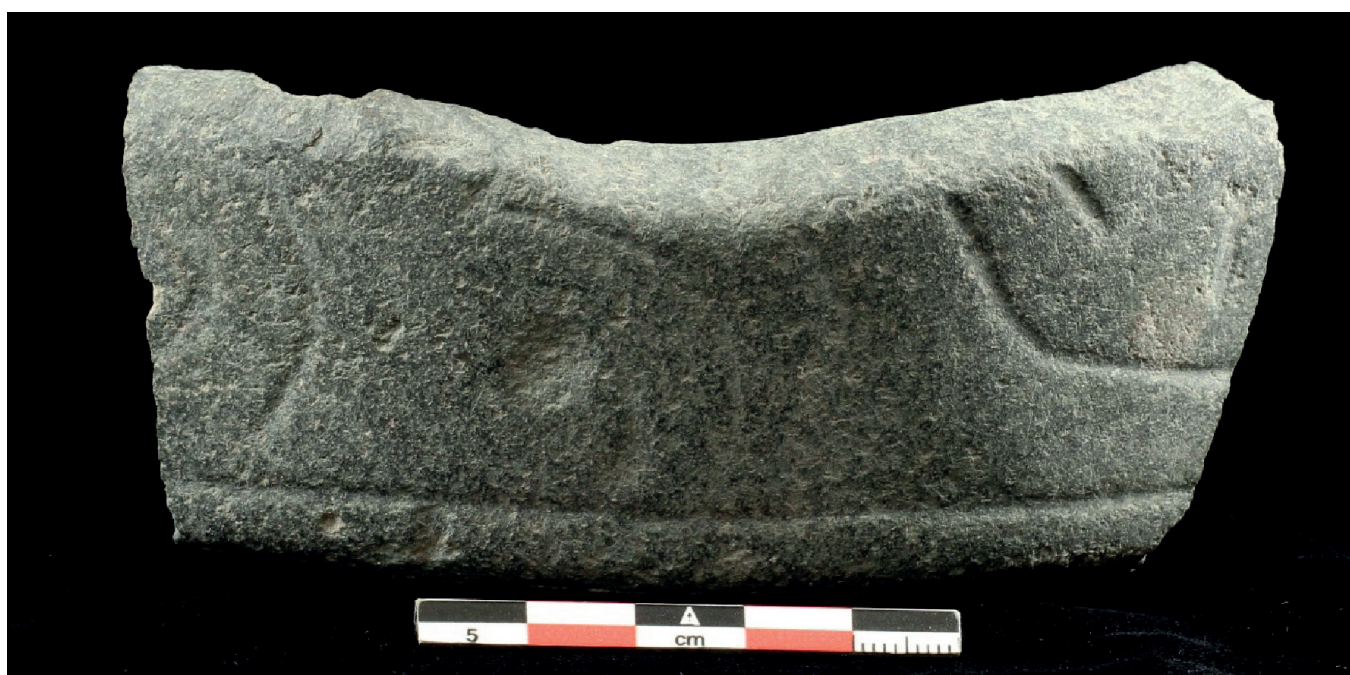

Fig. 4. Mortero decorado identificado en Loma Negra

(Fotografía: Gabriel Prieto)

Fig. 5. Principales tipos de ollas y fragmentos decorados, proveniente de Loma Negra.
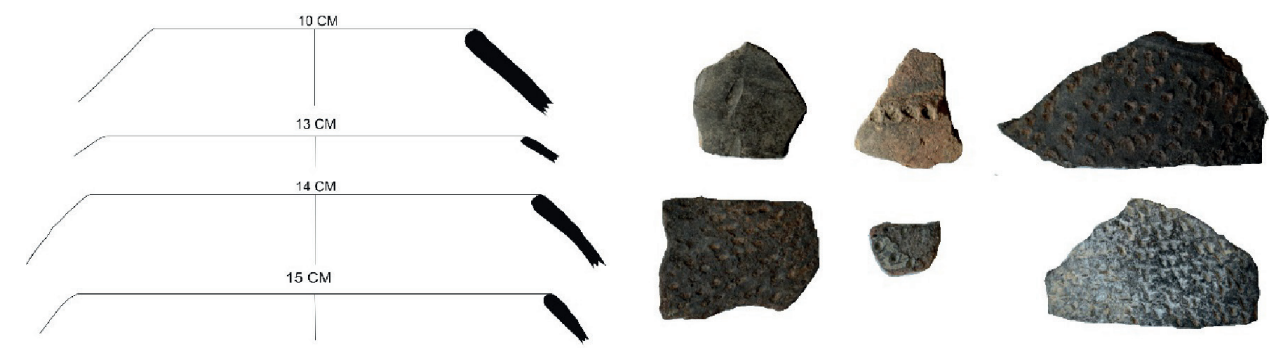

Fig. 6. Algunos especímenes mejor conservados de Capsicum sp. y Solanun Tuberosum, proveniente de nuestras excavaciones.

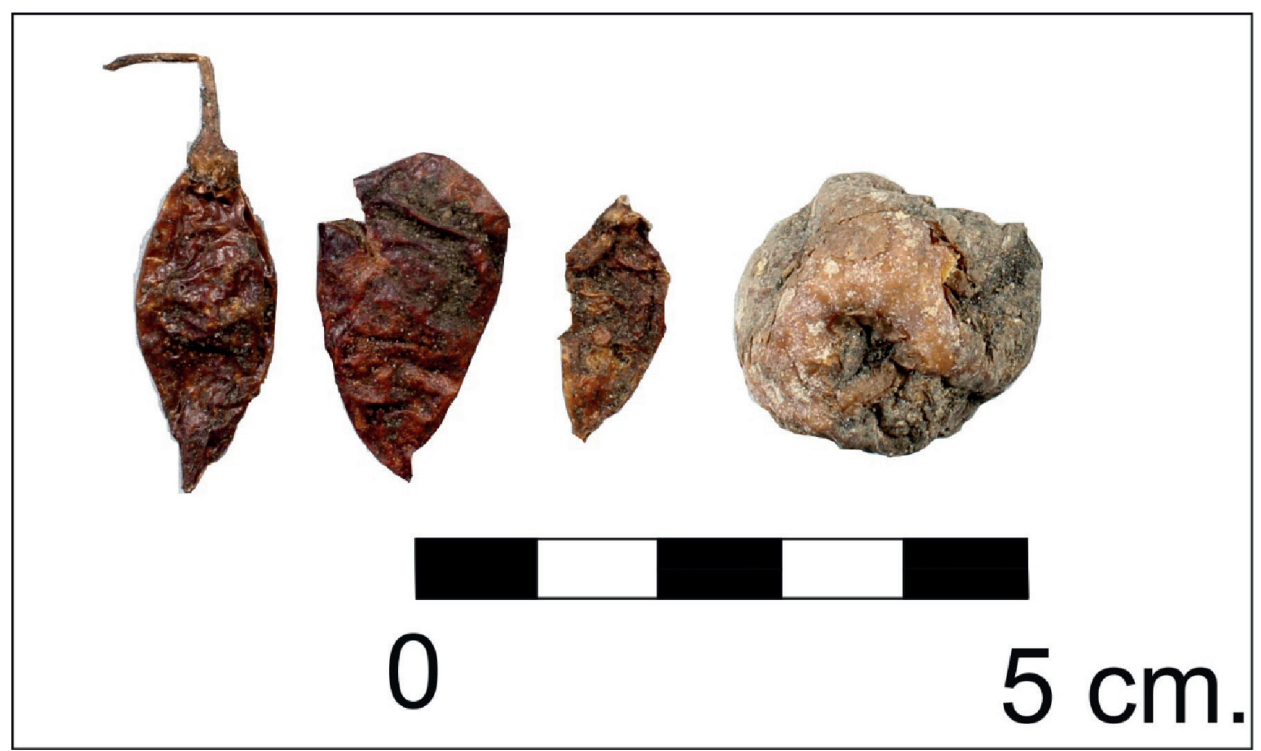

cual quedaban principalmente los frutos, y se hallaba frecuentemente. Con respecto a las aves y peces debemos mencionar que de igual manera pese al estado de conservación se pudo identificar especies de peces como Seriolella violácea, Sarda chilensis, Trachurus murphy, como las especies más importantes en cuanto a peces mientras en cuanto a aves no pudimos identificar especies debido al mal estado de conservación de los huesos pero inferimos que debieron haber consumido especies como Pelecanus thagus, Pelecanoides garnoti o Phalacrocorax bouganvilli, los que actualmente se pueden ver en las rocas y peñascos, siendo los pelicanos las aves más recurrentes en esta zona del litoral.

Los restos de moluscos y crustáceos son los que pudimos recuperar con mayor cantidad por encima de todos los materiales mencionados anteriormente, por 
lo que recuperamos importantes datos con respecto al consumo de especies malacológicas, de esta manera abundan especies como: Fissurella crassa, Aulacomya ater y Concholepas concholepas, en cuanto a crustáceos abunda el Plantixanthus orbingy (cangrejo violáceo).

\section{Breves reflexiones en torno a Loma Negra}

La presentación de este texto cuya finalidad es dar a conocer a la comunidad científica la existencia de un asentamiento del Periodo Inicial, en el litoral sur del valle de Casma, es de suma importancia porque nos ayudará a entender mejor de manera indirecta al gran complejo monumental de Las Aldas. En cuanto al asentamiento podemos inferir que debido al emplazamiento, estratigrafía y materiales recuperados podría tratarse de un asentamiento domestico con un espacio abierto en la cima, es decir al lado noreste del mismo para posibles actividades públicas. Este tipo de prácticas ya se han identificado en asentamientos de litoral del Periodo Inicial de la costa norte como Gramalote (Prieto, 2015), donde los pequeños asentamientos o aldeas del litoral, mantenían ciertos espacios para el uso público.

Podemos inferir que los habitantes de Loma Negra tuvieron una dieta abundante en recursos marinos, pero que supieron consumir otro tipo de alimentos como son los tubérculos, los cuales también han sido reportados en otros sitios contemporáneos y anteriores a este como Bahía Seca, Huaynuná, Tortugas, Las Aldas y Pampa de Las Llamas-Moxeke (Ugent et al., 1982). Un aspecto que nos falta aún por definir es la abundancia de ají (Capsicum sp.), ya que no es una planta que se caracterice principalmente por su aporte alimenticio, por lo que nos falta aún estudiar que otros usos pudo haber tenido. En cuanto a la presencia de frutos podemos inferir, que estos pudieron haber venido por un lado del valle y por el otro los pobladores de Loma Negra pudieron haber estado practicando algún tipo de horticultura en las lomas cercanas al asentamiento.

De igual manera, queda claro que los pobladores de Loma Negra debieron haber tenido contacto con su pares de Las Aldas, esto queda evidenciado en no sólo compartir las formas de las ollas sin cuello, sino también con la presencia de cerámica escarificada, semi escarificada y los punteados ovoides, identificados por Fung, para la Fase II de Las Aldas (Fung, 1969: 7174 ), por lo que creemos que este asentamiento tuvo relaciones muy estrechas con el asentamiento de Las Aldas, que podrían datar entre el 1400-1200 a. C.

De esta manera estamos ante un asentamiento, que probablemente mantuvo sus propios eventos públicos y tal vez sus propias ceremonias, altamente dinámico en cuanto a la explotación de recursos se refiere pues alternaron el consumo de especies marinas con diversas frutas que bien podrían obtener en las lomas o en el valle, los cuales supieron establecer lazos con sus asentamientos vecinos. Aún nos encontramos en proceso de estudiar estas dinámicas, por lo que nuevas excavaciones son necesarias para conocerlas.

\section{Agradecimientos}

Agradecemos a la National Geographic Society y Waitts Foundation por financiar nuestros trabajos de investigación. Al Dr. Gabriel Prieto por permitirnos usar los datos para esta publicación. A Rodolfo Monteverde, director del proyecto ante el Ministerio de Cultura y al recordado Erik Maquera por las extraordinarias imágenes aéreas obtenidas durante el proceso de registro de esta zona. De igual manera a los colegas que colaboraron con sus opiniones y puntos de vista sobre nuestros trabajos a fin de ayudarnos en relacionar mejor nuestros datos obtenidos y muy especialmente a CONCYTEC-Perú, por brindarme la beca que me permite dedicarme a tiempo completo a la investigación arqueológica. No quisiéramos terminar sin agradecer a los estudiantes y profesionales que nos apoyaron durante los análisis.

\section{Referencias bibliográficas}

BIRD, J. (1985). The preceramic excavations at The Huaca Prieta, Chicama Valley, Peru. New York. Anthropological papers of the American Museum of Natural History, New York.

Burger, R. (2009). Los Fundamentos Sociales de la Arquitectura Monumental del Periodo Inicial. En Burger, R. y K. Makowsky (Editores). Arqueología del Periodo Formativo en la Cuenca Baja de Lurin, pp 17-36. Fondo Editorial de la Pontificia Universidad Católica del Perú.

Chu, A. (2008). Bandurria: Arena, Mar y Humedal en el surgimiento de la civilización andina. Huacho. Lima 
Collier, D. (1962). Archaeological Investigations in the Casma Valley, Peru. 43 International Congress of Americanist, pp. 411-417.

Dillehay, T. (2016). Where the Lands meets the Sea: Fourteen Millennia of Human History at Huaca Prieta. Texas University Press.

Engel, F. (1970). Las lomas de Iguanily el Complejo de Haldas. Lima. Departamento de Publicaciones, Universidad Nacional Agraria La Molina.

Feldman, R. (1985). Preceramic Corporate Architecture: Evidence for the development of Non - egalitarian Social Systems in Peru. En C. Donnan (Editor), Early Ceremonial Architecture in The Andes. Pp.71 -92. Washington D.C. Dumbarton Oaks.

Fung, R. (1969). Las Aldas: su ubicación dentro del proceso histórico del Perú Antiguo. Dedalo vol. 9-10, pp. 1-207.

Fung, R. (1972). Nuevos Datos para el Periodo de Cerámica Inicial en el Valle de Casma. Arqueología y Sociedad $N^{o}$ 7-8, pp. 21-35.

Fung, R. (2004). El tempranos surgimiento en el Perú de los sistemas sociopolíticos complejos: planteamiento de una hipótesis de desarrollo original. En Quehaceres de la arqueología peruana, compilación de escritos, pp. 125-146. Lima. Museo de Arqueología y Antropología, Universidad Nacional Mayor de San Marcos.

Grieder, T. (1975). A Dated, Sequence of Building and Pottery at Las Haldas. Nawpa pacha N o 13. pp. 92-112.

Kaulicke, P. (2010). Las Cronologías del Formativo: 50 años de investigaciones japonesas en perspectiva. Lima. Fondo Editorial de la Pontificia Universidad Católica del Perú.

Lavallé, D. y M. Julien (2012). Prehistoria de la costa extremo - sur del Perú. Los pescadores arcaicos de la Quebrada de Los Burros (10000-7000 a. p). Lima. Instituto Frances de Estudios Andinos-Fondo Editorial de la Pontificia Universidad Católica del Perú.

Matsuzawa, T. (1978). The Formative Site of Las Haldas, Peru: Architecture, Chronology and Economy. American Antiquity vol. 43. pp. 652-673.

Moseley, M. (1975). The Maritime Foundations of Andean Civilizations. Menlo Park, California. Cummings Publishing Company.

Pozorski, S. y T. Pozorski (1987). Early Settlement and Subsistence in the Casma Valley, Peru. Iowa City. Iowa University Press.

Pozorski, S. y T. Pozorski (1990). Huaynuná a Late Cotton Preceramic Site on the North Coast of Peru. Journal of Field Archaeology vol. $17 N^{\circ} 1$. pp. 17-26.
Pozorski, S y T. Pozorski (1998). La dinámica del valle de Casma durante el Periodo Inicial. Boletín de Arqueología PUCP No2. pp. 83-100.

Pozorski, S. y T. Pozorski (2008). Early Cultural Complex on the Coast of Peru. En H. Silvermman y W. Isbell (Editores). Handbook of South American Archaeology. pp. 607-631. Springer Science.

Pozorski, T y S. Pozorski (1996). Ventilated Hearth in The Casma Valley, Peru. Latin American Antiquity vol. 7. $N^{o}$ 4. Pp. $341-353$.

Pozorski, T y S. Pozorski (1999). Una reevaluación del desarrollo de la sociedad compleja durante el Precerámico Tardío en base a los fechados radiocarbónicos y a las Investigaciones Arqueológicas en el Valle de Casma. Boletin de Arqueología PUCP No3. pp.171 -186.

Prieto, G. (2015). Gramalote: Domestic Life, Economy and Ritual Practice of a Prehispanic Maritime Community. Dissertation of Ph.D. Yale University.

Prieto, G. y F. Freire (2013). Por la Ruta del Pescado: Asentamientos y caminos prehispánicos de Pescadores - Mariscadores en el Litoral Sur del Rio Casma, Costa Norte del Perú. En Arkinka vol. 213. pp. 100-111.

Prieto, G., L. Arrelucea y R. Monteverde. (2017). Excavaciones y Prospecciones en el Litoral Sur del Valle de Casma. (manuscrito en posesión del autor).

Rosas, H. (1970). La Secuencia Cultural del Periodo Formativo en Ancón. Tesis para optar el Titulo de Bachiller en Arqueología. Universidad Nacional Mayor de San Marcos.

Strong, W. y C. Evans (1952). Cultural Stratigraphy in the Viru Valley, Northern Peru: The Formative and Florescent Epochs. Columbia Studies in Archaeology and Ethnology, vol. 4. Nueva York. Columbia University Press.

Tello, J. (1956). Arqueología del Valle de Casma. Culturas Chavin, Santa o Huaylas Yunga y Sub-Chimú. Lima. Museo de Arqueología y Antropología, Universidad Nacional Mayor de San Marcos.

Uceda, S. (1992). Industrias Líticas Precerámicas en Casma. En D. Bonavia y R. Matos (Editores). Arqueología Peruana, pp 45-67. Lima. Fomciencias.

Uhle, M. (1906). Los “Kjockkenmoedings” del Perú. Revista Histórica del Perú 1. pp. 3-23. Lima.

Ugent, D., S. Pozorski y T. Pozorski (1982). Archaeological Potato Tuber Remains form The Casma Valley of Peru. Economic Botany 38. pp. 182192.

Ugent, D., S. Pozorski y T. Pozorski (1986). Archaeological Manioc from Coastal Peru. Economic Botany 40, pp. 78-102. 